Annemieke Visser

Gea A. Huizinga

Harald J. Hoekstra

Winette T. A. van der Graaf

Josette E. H. M. Hoekstra-Weebers

\section{Temperament as a predictor of internalising and externalising problems in adolescent children of parents diagnosed with cancer}

Received: 4 April 2006

Accepted: 22 June 2006

(C) Springer-Verlag 2006
Published online: 30 August 2006

\author{
J. E. H. M. Hoekstra-Weebers $(\bowtie)$ \\ Psychosocial Services, \\ University Medical Center Groningen, \\ P.O. Box 30.001, 9700 RB \\ Groningen, The Netherlands \\ e-mail: j.hoekstra-weebers@psb.umcg.nl \\ Tel.: +31-50-3614978 \\ Fax: $+31-50-3619326$
}

\section{A. Visser - G. A. Huizinga .}

J. E. H. M. Hoekstra-Weebers

Department of Health Psychology,

University of Groningen and

University Medical Centre Groningen,

P.O. Box 30.001, 9700 RB

Groningen, The Netherlands

\section{H. J. Hoekstra}

Department of Surgical Oncology, University of Groningen and University Medical Centre Groningen, P.O. Box 30.001, 9700 RB

Groningen, The Netherlands

\section{W. T. A. van der Graaf}

Department of Medical Oncology,

University of Groningen and

University Medical Centre Groningen,

P.O. Box 30.001, 9700 RB

Groningen, The Netherlands

J. E. H. M. Hoekstra-Weebers

Department of Psychosocial Services,

University of Groningen,

P.O. Box 30.001, 9700 RB

Groningen, The Netherlands

\begin{abstract}
Objective: This study examined the relationship between temperament and internalising and externalising problems among children of parents diagnosed with cancer, beyond the effects of sociodemographics, illness-related variables and life events. Materials and methods: Three hundred and forty adolescent children and their 212 parents diagnosed with cancer participated. Children and parents completed the Youth Self Report and the Child Behaviour Checklist, respectively. Children completed also the Early Adolescent Temperament Questionnaire. Main results:

Daughters of parents with cancer were reported as having more internalising problems than their counterparts did. Prevalence of problems did not depend on children's and parents' age or educational level. Recurrent
\end{abstract}

disease and number of life events experienced by children and parents affected the problems reported. The most important temperament dimensions in the prediction of internalising problems in children were shyness and fear/worry, to a lesser extent, frustration and perceptual sensitivity (children only) and lower scores on pleasure intensity (parents only). Externalising problems were associated with effortful control and in children's reports with frustration. Temperament seemed to be a more important predictor of problems reported by children than parents. Conclusion: Findings suggest that temperament is useful in determining the relative vulnerability of children of parents who have been diagnosed with cancer. Social workers may help parents to recognise individual differences between children and to support children by using techniques that are compatible with the temperament of children.

Keywords Parental cancer . Internalising and externalising problems - Adolescents · Temperament $\cdot$ Life events

\section{Introduction}

All people are confronted with intense experiences during the course of their lifetime. Even children are not spared from them. Adolescent children, especially, are vulnerable to stressful events [1]. One stressful incident with which families with adolescent children are increasingly confronted is the diagnosis of cancer in one of the parents. Studies have shown that adolescent children in such situations, the daughters particularly, experience more 
emotional problems than their age peers do [2, 3]. Although the functioning of children of cancer patients has received increasing attention, research into risk and resilience factors is still in its infancy. Recent studies found evidence for the impact of parental characteristics [4], parent-child communication [5] and family functioning [6] on child functioning. Increased attention is given to the different effect of parental cancer for boys and girls and children of different ages, but research into other child characteristics is lacking. Temperament is one of the factors that may have an important influence on how children cope with stressful events, and therefore why some children are more vulnerable to the development of problems than others [7]. The primary hypothesis of most models of temperament is that specific dimensions are related to prevalence of specific problems. Research into the role of temperament can provide insight into which children are at greater risk in such situations and which children are better equipped to handle the situation.

The developmental model of temperament as proposed by Rothbart and Derryberry is one of the few models that offers a measurement tool that is specifically designed for use with adolescents, and it was therefore used in the present study. Rothbart proposes that temperament is relatively stable, but that the expression of temperament can change as a result of maturation and (social) environmental influences, including life events $[8,9]$. The model distinguishes between two concepts: reactivity and self-regulation. Reactivity is comprised of the physical and emotional differences that exist among individuals in reaction to stress. Children who have a high degree of reactivity are more easily upset and need more time to recover than other children do. The term "self-regulating system" refers to such processes as attention, activation and inhibition. These processes have an important influence on the regulation of emotions and behaviour. These children may be able to direct attention away from the stressor, such as parental cancer.

To our knowledge, no studies have reported on the effect of different temperament dimensions on the functioning of children of parents who have been diagnosed with cancer. The aim of the current study was to investigate the effects of temperament on prevalence of problems in these children, beyond the possible effects of socio-demographics (age, gender, educational level), illness-related variables (recurrent disease and time since diagnosis) and the number of negative life events that children experienced during the year before assessment.

\section{Materials and methods}

\section{Procedure}

Between January 2001 and February 2003, written information on this study was offered to all cancer patients who were consecutively hospitalised or who visited the outpatient's clinic at the University Medical Centre Groningen by their physicians or oncology nurses. In addition, information was sent to patients and their family members who had contacted the researchers in response to media attention because they wished to participate in the study. Families were eligible if patients had been diagnosed between 1 to 5 years before study entry and if they had children between 4 to 18 years of age. Participants had to be fluent in Dutch. Patients discussed study participation with their partners (if present) and children. Informed consent was obtained according to the regulations of the Medical Ethical Committee of the University Medical Centre Groningen. After informed consent was received, questionnaires and prepaid return envelopes were provided.

Participants were guaranteed that answers were treated absolutely confident and will be described completely anonymous.

\section{Participants}

The current study is part of a larger study in which 476 families with children aged 4 to 18 years were approached, and information was mailed to 110 families who had contacted us for information about participation. Of these, 205 families from the first group and 89 families from the second group consented to participate (response: 43 and $81 \%$, respectively). Ill parents who did not participate did not significantly differ from those who participated with respect to gender, tumour type and time since diagnosis.

The current study focused on the responses of children of 11 years of age and older, as they completed the questionnaires themselves. The sample for the present study consisted of 340 adolescent children (149 sons and 191 daughters), between the ages of 11 and 18 years (mean age $=14.9$ years, $S D=2.3)$ and their 212 ill parents $(80 \%$ mothers, mean age $=45.4$ years, $\mathrm{SD}=4.7)$. Twenty-one percent of the children were receiving education in primary school, $9 \%$ at the lower vocational level, $17 \%$ in lower general secondary education, $12 \%$ in intermediate vocational education, 38\% in high school and 3\% in higher vocational education or university. Nine percent of the children were from single-parent families. Parents (43 fathers; 169 mothers, mean age $=45.4$ years, $S D=4.7$ ) had been diagnosed with various types of cancer: breast $(55 \%)$, haematological $(9 \%)$, skin $(9 \%)$, gynaecological $(9 \%)$, urological (5\%), bone tumours (4\%), gastrointestinal (5\%) or other cancers, such as cancer of the central nervous system or head and neck cancer $(6 \%)$. The mean time since diagnosis was 2.6 years $(\mathrm{SD}=1.2)$. Twenty-nine percent of the parents had suffered relapses.

Children and parents approached in the hospital did not significantly differ in age or gender from children and parents who had volunteered for participation. Educational level of parents of the last-named group was significantly 
higher $(t=5.8, p \leq 0.001)$ than that of the first-named group, but this was not found for children's educational level. Furthermore, children and parents in both groups reported similar levels of internalising and externalising problems, and children did not differ significantly in temperament.

\section{Measures}

Temperament Temperament was measured using the adolescent version of the Revised Early Adolescent Temperament Questionnaire (EATQ-R) of Rothbart and Derryberry [10-12]. The EATQ-R consists of 53 items and includes ten subscales that are designed to measure temperamental attention control, activation control, inhibitory control, high intensity pleasure, shyness, fear, frustration, affiliation, perceptual sensitivity and pleasure sensitivity. Answers were rated on a 5-point Likert-type scale $(1=$ "almost always untrue" to $5=$ "almost always true"). Higher values represent a higher availability of the temperamental dimension concerned. The psychometric quality of the EATQ-R was reported to be sufficient among American adolescents with Cronbach's alpha's ranging from $\alpha=0.55$ to $\alpha=0.78$ [13]. In the present study, alpha scores ranged from $\alpha=0.36$ to $\alpha=0.74$, and mean inter-item correlations from $r=0.11$ to $r=0.37$. Five of the ten dimensions had mean inter-item correlations of $<0.20$. Therefore, factor analyses were carried out to study the extent to which the temperamental dimensions identified by Rothbart and colleagues emerged from the data of the present Dutch study (see preliminary analyses).

Internalising and externalising problems The Youth SelfReport (YSR) and Child Behaviour Checklist (CBCL) were used to assess, respectively, adolescent children's self-reported and parent's reported behavioural and emotional problems in children [14-16]. The YSR/CBCL consists of $102 / 120$ problem items with three response options $(0=$ not true, $1=$ somewhat or sometimes true and $2=$ very true or often true). Higher scores indicated more problems. The Internalising (TIS) and Externalising Behaviour Problem Scales (TES) were used in the present study. The internalising scale (32 items) consists of the syndrome subscales withdrawal, somatic complaints and anxiety/depression. The externalising scale (30 items) consists of the syndrome subscales delinquent behaviour and aggressive behaviour. The YSR is one of the most commonly used questionnaires in adolescent research. Cronbach's alpha scores in the present study were high $(\alpha>0.80)$. The manual provides norm data based on a randomly selected Dutch sample of 560 adolescent boys and 564 adolescent girls.
Life events The Questionnaire of Recently Experienced Events was used to ask children and parents about the number of life events experienced during the past year. This questionnaire is based on the Recent Life Change Questionnaire (RLCQ) developed by Rahe [17]. Questions measuring negative events (14 items; e.g., divorce, illness by other family members than the parent with cancer) were used.

\section{Analyses}

Factor analyses of the EATQ-R were executed using Simultaneous Confirmatory Analysis (SCA) and Exploratory Principal Component Analysis (PCA) to investigate factor validity.

Chi-square and $t$ tests were performed to compare children and parents who had been recruited in the hospital and those who had volunteered for participation on demographic characteristics and the problems reported.

One-sample $t$ tests were performed to compare prevalence of internalising and externalising problems reported by children and parents diagnosed with cancer with those of the norm group.

Univariate statistics ( $t$ tests and pearson correlation analyses) were performed to investigate effects of study variables (age, gender, educational level, time since diagnosis, recurrence, number of negative life events, and temperament) and problems in children.

Hierarchical regression analyses were conducted to examine the contribution of temperament dimensions to prediction of internalising and externalising problems in children. Socio-demographics and illness-related variables (first step), and number of life events (second step) significantly related to temperament were entered into regression analyses to ensure that any effect found for temperament (third step) on children's problems would not be attributed to these variables. To examine whether multicollinearity exists between the independent variables, Pearson correlation analyses and Variance Inflation Factors (VIF) were performed. If the mean VIF is considerably larger than one and the largest VIF is greater than 10, multicollinearity exists [18].

There is evidence that sons and daughters may respond differently to the cancer in the parent [19] and that they differ in temperament $[13,20]$. Two-way-interaction terms (using standardised scores) were computed to examine whether the pattern of the relationship between temperament and prevalence of problems differ between sons and daughters. Only when the 2-way interaction accounted for a unique significant effect was it included in the model.

Owing to the large number of comparisons in relation to the sample size significance was set at $p \leq 0.01$. 


\section{Results}

\section{Preliminary analyses}

Simultaneous Confirmatory Analysis (SCA) was conducted to examine differences in the percentage of variance explained by the original structure and by the exploratory structure over the same number of factors. The difference in the variance explained by the original structure (41.0\%) and by the exploratory structure $(46.1 \%)$ was considered too large ( $>2 \%$ rule of thumb, [21]) to continue with the original structure. An exploratory Principal Component Analysis (PCA) was conducted using orthogonal rotation followed by varimax procedure. The number of constituting factors was determined based on the scree test. Items that loaded consistently low $(<0.30)$ or on varying components were excluded. In addition, all itemsparticularly those with loadings between 0.30 and 0.40 were critically examined for the degree to which they formed a good reflection of the dimensions on which they loaded (face validity). Dimensions were assessed as consistent by an alpha above 0.60 and an inter-item correlation above 0.20 . On the basis of these criteria, 17 items were excluded, including the entire inhibition-control (five items) and the affiliativeness scale (five items). Thirty-six items remained, distinguishing seven temperamental dimensions. The first dimension was called effortful control and consists of all five items from activation control and four of the six items from attention control. One of the attention control items was excluded and the other was added to the original four perceptual sensitivity items ("I am good at keeping track of several things that are happening around me") that represent the second dimension. The third dimension is pleasure sensitivity; just one item did not meet the criteria and was excluded. The fear/ worry dimension forms the fourth dimensions. Three of the six items loaded on this scale. One of the other items was excluded, one was added to pleasure intensity ("I get frightened when I ride with a person who likes to speed"), and one was added to the original four items of the shyness scale ("Some of the kids at school make me nervous..."). Shyness was the fifth dimension. The sixth dimensions form the pleasure intensity. Three of the six items loaded low or were not consistent, and were therefore excluded. The seventh dimension forms frustration. One of the seven items did not meet the criteria and was excluded. The seven temperamental dimensions can be defined as follows. Effortful control measures the capacity to start and persist in an action and to focus attention. Pleasure sensitivity is the pleasure related to stimuli involving low intensity, complexity, novelty and incongruity. Perceptual sensitivity pointed to detection or perceptual awareness of slight, lowintensity stimulation in the environment. Pleasure intensity represents the pleasure derived from activities involving high intensity. Shyness is the behavioural inhibition to novelty and challenge, especially social. Frustration measures the negative effect related to interruption of ongoing tasks or goal blocking. Fear/worry represents the worry for occurrence of unpleasant situations. The seven factors that were formed of remaining items explained $47.2 \%$ of the variation. Alpha coefficients from the other dimensions ranged from $\alpha=0.61$ to $\alpha=0.79$, and inter-item correlations ranged from $r=0.21$ to $r=0.48$ (Table 1 ).

Cross validity The same research group conducted a prospective study among children of parents recently diagnosed (1-16 weeks ago) with cancer using a similar procedure in approaching families as was used in the current study. The adapted structure was tested among 144 adolescent children $(54 \%$ daughters; mean age $=14.2$ years, $\mathrm{SD}=2.3$ years) that participated in the prospective study (comparison group). Results of PCA among children in the prospective study were similar to those found in the current study. The internal consistency and mean interitem correlations of the two groups were comparable (Table 1). Results of the Principal Components Factor Analysis are available on request.
Table 1 Cronbach's alpha EATQ-R dimensions of children in the current study and a control study

\begin{tabular}{|c|c|c|c|c|c|}
\hline \multirow[t]{2}{*}{ Dimensions } & \multicolumn{2}{|c|}{ Current study } & \multicolumn{3}{|l|}{ Control } \\
\hline & $\begin{array}{l}\text { Cronbach's } \\
\text { alpha }\end{array}$ & $\begin{array}{l}\text { Mean inter-item } \\
\text { correlations }\end{array}$ & $\begin{array}{l}\text { Cronbach's } \\
\text { alpha }\end{array}$ & $\begin{array}{l}\text { Mean inter-item } \\
\text { correlations }\end{array}$ & $\begin{array}{l}\text { Number } \\
\text { of items }\end{array}$ \\
\hline $\begin{array}{c}\text { Effortful } \\
\text { control }\end{array}$ & 0.75 & 0.26 & 0.74 & 0.25 & 9 \\
\hline $\begin{array}{l}\text { Pleasure } \\
\text { sensitivity }\end{array}$ & 0.79 & 0.36 & 0.83 & 0.56 & 4 \\
\hline Shyness & 0.69 & 0.30 & 0.63 & 0.25 & 5 \\
\hline Frustration & 0.61 & 0.21 & 0.69 & 0.27 & 6 \\
\hline $\begin{array}{l}\text { Perceptual } \\
\text { sensitivity }\end{array}$ & 0.62 & 0.25 & 0.70 & 0.31 & 5 \\
\hline Pleasure intensity & 0.71 & 0.37 & 0.74 & 0.42 & 4 \\
\hline Fear/worry & 0.61 & 0.34 & 0.61 & 0.35 & 3 \\
\hline
\end{tabular}


Internalising and externalising problems in children

$T$ tests revealed no significant differences in prevalence of internalising and externalising problems between sons and norm group boys as reported by themselves and their ill parents. Daughters and their ill parents reported significantly more internalising problems than found in norm group girls (Table 2).

Children's problems and socio-demographics, illnessrelated variables and life events

Socio-demographics Daughters experienced significantly more internalising problems than sons as was reported by ill parents and self-reports $(t=2.9, p=.004 ; t=4.8, p \leq 0.001)$. Neither children's age and educational level, nor parent's age, gender or educational level were significantly related to the prevalence of problems reported in children.

Illness-related variables Parents and children reported more internalising problems in case of recurrent disease than in case of primary disease $(t=-3.29, p \leq 0.001 ; t=-3.18$, $p=0.002$, respectively). Time since diagnosis was not significantly associated with reports of either internalising or externalising problems (even after controlling for recurrent disease).

Life events The number of negative life events children or parents experienced during the preceding year was significantly positively correlated with internalising $(r=0.36, p \leq 0.001, r=0.25, p \leq 0.001$, respectively) and externalising problems $(r=0.25, p \leq 0.001)$ reported by or in children.

Children's temperament and socio-demographics, illness-related variables and life events

Socio-demographics Sons had significantly higher mean scores on pleasure intensity $(t=4.7, p \leq 0.001)$ and significantly lower scores on shyness $(t=-2.8, p=0.005)$ than daughters did. Age of children was significantly negatively related to effortful control $(r=-0.18, p \leq 0.001)$. No relationship was found between child's educational level and temperament.
Illness-related variables No significant relationships were found between length of time since diagnosis and children's temperament. Children of parents who had recurrent disease differed significantly in fear/worry from children of parents with primary disease $(t=3.1, p=0.002)$.

Life events Number of negative life events experienced was significantly positively correlated with pleasure sensitivity $(r=0.15, \quad p=0.007)$, perceptual sensitivity $(r=0.15, p=0.005)$ and fear/worry $(r=0.30, p \leq 0.001)$ and negatively with effortful control $(r=-0.15, p=0.008)$.

Relationships between temperament and problems in children

All temperament dimensions were significantly related to children's self-reported internalising problems. Shyness, pleasure intensity and fear/worry were significantly related to internalising problems as reported by ill parents. Effortful control, frustration and fear/worry were significantly associated with the prevalence of externalising problems in children as reported by children and parents (Table 3).

Predictors of internalising and externalising problems

Internalising problems Child's gender and recurrent disease explained a significant percentage of the variance in the prevalence of internalising problems in child's $\left(R^{2} \mathrm{Ch}=0.10\right)$ and parent's reports $\left(R^{2} \mathrm{Ch}=0.08\right)$. Both variables appeared to have a significant independent effect. Life events accounted for a significant increment in explained variance in child's $\left(R^{2} \mathrm{Ch}=0.10\right)$ and parent's reports $\left(R^{2} \mathrm{Ch}=0.07\right)$. The temperament dimensions predicted a significant percentage of additional variance in children's $\left(R^{2} \mathrm{Ch}=0.27\right)$ and parent's reports $\left(R^{2} \mathrm{Ch}=0.04\right)$. Shyness, frustration, perceptual sensitivity and fear/worry appeared to have a significant positive independent effect in children's reports. None of the variables appeared to have a significant independent effect in parent's reports. Interaction terms between temperament dimensions and child's gender failed to contribute significantly to the prediction of internalising problems in children and

Table 2 Descriptive statistics of the YSR and one sample $t$ tests for comparison of study and norm group

\begin{tabular}{|c|c|c|c|c|c|c|c|c|c|c|}
\hline & \multicolumn{2}{|l|}{ Sons } & \multicolumn{2}{|c|}{ Norm group boys } & \multirow[t]{2}{*}{$t$} & \multicolumn{2}{|c|}{ Daughters } & \multicolumn{2}{|c|}{ Norm group girls } & \multirow[t]{2}{*}{$t$} \\
\hline & Mean & SD & Mean & SD & & Mean & $\mathrm{SD}$ & Mean & $\mathrm{SD}$ & \\
\hline Internalising problems YSR & 9.6 & 7.3 & 8.6 & 5.8 & 1.6 & 13.9 & 9.9 & 10.8 & 7.1 & $4.3^{*}$ \\
\hline Externalising problems YSR & 11.4 & 6.2 & 11.5 & 6.7 & -0.2 & 10.8 & 6.2 & 10.0 & 6.1 & 1.7 \\
\hline Internalising problems CBCL & 6.1 & 6.2 & 5.7 & 5.7 & 0.8 & 8.4 & 7.2 & 6.5 & 6.0 & $3.5^{*}$ \\
\hline Externalising problems CBCL & 6.6 & 6.1 & 7.1 & 7.1 & -0.9 & 5.9 & 6.0 & 5.5 & 5.8 & 0.9 \\
\hline
\end{tabular}

$* p<0.001$ 
Table 3 Descriptive statistics of the temperament dimensions and correlations of these variables with internalising and externalising problems

\begin{tabular}{|c|c|c|c|c|c|c|}
\hline \multirow[t]{2}{*}{ Temperament } & \multirow[t]{2}{*}{ Mean } & \multirow[t]{2}{*}{ SD } & \multicolumn{2}{|l|}{ Children } & \multicolumn{2}{|l|}{ Ill parents } \\
\hline & & & $\begin{array}{l}\text { Internalising } \\
r\end{array}$ & $\begin{array}{l}\text { Externalising } \\
r\end{array}$ & $\begin{array}{l}\text { Internalising } \\
r\end{array}$ & $\begin{array}{l}\text { Externalising } \\
r\end{array}$ \\
\hline $\begin{array}{c}\text { Effortful } \\
\text { control }\end{array}$ & 27.8 & 6.2 & $-0.25 * *$ & $-0.44 * *$ & -0.05 & $-0.24 * *$ \\
\hline Pleasure sensitivity & 11.2 & 4.0 & $0.22 * *$ & 0.03 & 0.13 & -0.04 \\
\hline Shyness & 12.0 & 3.8 & $0.30 * *$ & 0.00 & $0.19 * *$ & -0.13 \\
\hline Frustration & 18.4 & 3.8 & $0.29 * *$ & $0.36^{* *}$ & 0.10 & $0.14^{*}$ \\
\hline Perceptual sensitivity & 16.4 & 3.5 & $0.15^{*}$ & 0.07 & -0.01 & -0.09 \\
\hline Pleasure intensity & 14.7 & 3.7 & $-0.18 * *$ & -0.02 & $-0.19 * *$ & 0.10 \\
\hline Fear/worry & 7.4 & 2.7 & $0.46^{* *}$ & $0.29 * *$ & $0.23 * *$ & $0.16^{*}$ \\
\hline
\end{tabular}

$* p<0.01$

$* * p<0.001$

\section{Discussion and conclusion}

models accounted $19 \%$ of the variance in child's and parents' models, respectively (Table 4). VIFs ranged between 1.0-1.3, suggesting that there was no problem of collinearity.

Externalising problems Life events accounted for a significant percentage of the explained variance in children's reports $\left(R^{2}=0.07\right)$. The temperament dimensions accounted for a significant increment in children's $\left(R^{2} \mathrm{Ch}=0.22\right)$ and parent's reports $\left(R^{2} \mathrm{Ch}=0.07\right)$. Effortful control had a significant unique negative effect for both children and parent, and frustration also for children's reported externalising problems. The interaction terms did not contribute significantly to the problems reported. The variables entered into children's and parents' models explained 29 and $7 \%$, respectively, of the variance (Table 5). VIFs in both models were acceptable, ranging between 1.1-1.2.
The present study is the first to examine the contribution of temperament to prevalence of problems among adolescent children of parents diagnosed with cancer. The findings suggest that temperament predicted internalising and externalising problems, beyond the effects of sociodemographics (child' gender), illness-related variables (recurrent disease) and number of negative life-events. The most powerful temperament dimensions for internalising problems were shyness and fear/worry (reactive factor). To a lesser extent, frustration and perceptual sensitivity (children's reports only) heighten the risk for internalising problems. It was argued that shy and anxious children generally have a tendency to withdraw and are hesitant to seek support from their surroundings [22], whereas seeking support might be important, especially in situations in which a parent had cancer. High levels of frustration are

Table 4 Regression analyses examining temperament as a predictor of internalising problems reported by children and ill parents

\begin{tabular}{|c|c|c|c|c|c|c|c|c|}
\hline & \multicolumn{4}{|l|}{ Children } & \multicolumn{4}{|c|}{ Ill parents } \\
\hline & \multicolumn{4}{|c|}{ Internalising problems } & \multicolumn{4}{|c|}{ Internalising problems } \\
\hline & Beta & $R^{2}$ & $R^{2} \mathrm{Ch}$ & $\mathrm{FCh}$ & $\overline{B e t a}$ & $R^{2}$ & $R^{2} \mathrm{Ch}$ & $\mathrm{FCh}$ \\
\hline Step 1 & & 0.10 & & $17.1^{* *}$ & & 0.08 & & $13.5^{* *}$ \\
\hline Child's gender & $-0.25 * *$ & & & & $-0.18 * *$ & & & \\
\hline Recurrent disease & $0.20 * *$ & & & & $0.22 * *$ & & & \\
\hline Step 2 & & 0.20 & 0.10 & $40.6^{* *}$ & & 0.15 & 0.07 & $24.4^{* *}$ \\
\hline Negative life events & $0.33 * *$ & & & & $0.26^{* *}$ & & & \\
\hline Step 3 & & 0.48 & 0.27 & $22.8^{* *}$ & & 0.19 & 0.04 & $5.3^{* *}$ \\
\hline Effortful control & -0.10 & & & & - & & & \\
\hline Pleasure sensitivity & 0.09 & & & & - & & & \\
\hline Shyness & $0.31 * *$ & & & & 0.10 & & & \\
\hline Frustration & $0.15^{* *}$ & & & & - & & & \\
\hline Perceptual sensitivity & $0.12 *$ & & & & - & & & \\
\hline Pleasure intensity & 0.02 & & & & -0.09 & & & \\
\hline Fear/worry & $0.25^{* *}$ & & & & 0.13 & & & \\
\hline
\end{tabular}

The dashes indicate that variables were not entered into the model because no significant univariate relationship was found. $* p<0.01$ $* * p<0.001$ 
Table 5 Regression analyses examining temperament as a predictor of externalising problems as reported by children and ill parents

\begin{tabular}{|c|c|c|c|c|c|c|c|c|}
\hline & \multicolumn{4}{|l|}{ Children } & \multicolumn{4}{|c|}{ Ill parents } \\
\hline & \multicolumn{4}{|c|}{ Externalising problems } & \multicolumn{4}{|c|}{ Externalising problems } \\
\hline & Beta & $R^{2}$ & $R^{2} \mathrm{Ch}$ & $\mathrm{FCh}$ & Beta & $R^{2}$ & $R^{2} \mathrm{Ch}$ & $\mathrm{FCh}$ \\
\hline Step 1 & & 0.07 & & $22.6^{* *}$ & & & & \\
\hline Negative life events & $0.26^{* *}$ & & & & - & & & \\
\hline Step 2 & & 0.29 & 0.22 & $33.7 * *$ & & 0.07 & & $7.9 * *$ \\
\hline Effortful control & $-0.33 * *$ & & & & $-0.21 * *$ & & & \\
\hline Frustration & $0.23 * *$ & & & & 0.06 & & & \\
\hline Fear/worry & 0.10 & & & & 0.10 & & & \\
\hline
\end{tabular}

The dash indicates that the variable was not entered into the model because no significant univariate relationship was found. $* p<0.01$

$* * p<0.001$

related to reduced ability to regulate attention and emotions, whereby children are less able to relax and direct themselves toward matters other than the stressor [23]. Withdrawn behaviour, anxiety and depression might be consequences of these tendencies. Internalising problems reported by the child also increase when they were highly sensitive to things and people around them (perceptual sensitivity). Although, Rothbart and Bates (1998) hypothesised that children with this kind of sensitivity are more vulnerable for internalising and externalising problems, research on these dimensions is lacking [9]. The relationships between shyness, anxiety and frustration and internalising problems found in children reports have also been found in studies among the general population [9, 24-26].

Those who have a temperament characterised by a low level of effortful control (regulative factor) and a high level of frustration are more at risk to develop externalising problems. The relationship between effortful control and externalising problems has been found in other studies as well [9, 11, 26-29]. Children who have more control show more initiative in undertaking activities, have more ability to shift their attention and to focus and are less easily distracted by circumstances [27]. The control that children have over their behaviour in this regard decreases the chance of externalising problems. As mentioned above, frustration decreases emotional regulation and can lead to externalising problems, in addition to manifesting itself in internalising problems [25]. No effect was found for pleasure intensity, which was in contrast to the results of a recent study among children in the general population. That study found that children who scored high on pleasure intensity experienced more externalising problems [26].

Whether the relationship between temperament and problems is specific for situations in which children are exposed to a parent with cancer, is not clear. It is argued that reactive and regulative temperament factors really are important when the child experienced stressful events [30]. A stressful event, such as illness in the parent brings forth negative emotions, specifically in children high in emotionality. Children with low levels of effortful control may have difficulties to deal with these emotions, and may develop as a consequence emotional or behavioural problems [30].

Although the sons and daughters differed in the problems experienced and in their temperament, the relationship between temperament and problems were similar for both genders, as was found in a previous study [26].

Similar patterns were found for parent's and self reported problems and temperament in the current study, according to a previous study [26]. Our results showed, however, a stronger relationship between temperament and the problems reported by children than parents' reports of problems, whilst Oldehinkel and colleagues found the opposite. This inconsistency may be attributed to the informant; Oldehinkel and colleagues used parents' reports to examine temperament, whereas the current study used self-reports from children. A number of studies found that parents and children perceived the level of problems of children under these circumstances different [19, 31]. The differences in perception may have caused also the differences between parents and children found in the present study.

Another interesting result from this study is that, four of the seven temperament dimensions were related to the number of negative life events experienced. This is consistent with Rothbert's theory, which suggests that, despite its biological base, temperament is influenced by experiences. The influence of stressful environmental factors on the development of temperament is an interesting phenomenon. Because the current study uses a crosssectional design, no causal statements can be derived from the results.

The current study is one of few to use self-reports of temperament from a large number of children to examine the relationship between temperament and internalising and externalising problems. It is generally assumed that self-description is an important source of information in the field of personality research. Nonetheless, it was faced with 
some difficulties. First, Rothbart and colleagues paid a lot of attention to the development of the theory around temperament. The empirical implementation of the EATQ$\mathrm{R}$, however, was limited. The original structure of the EATQ-R seemed not applicable for the Dutch children in the current study. A recent study among Dutch adolescents reported also some problems with the self-reported version of the EATQ-R [26] and used, therefore, the parent version. Furthermore, the comparison of results from the current study with those of studies that used other theories of temperament was difficult, due to differences in conceptualizing and in labelling with regard to corresponding dimensions. More research using reliable, validated instruments to investigate the temperament of children is necessary. Second, some of the items used to measure temperament resemble items on the problem scale and can cause item-overlap. Previous studies show that the association between constructs remains essentially the same when correcting for possible overlapping items [26, 32, 33] indicating that they are separate concepts. To examine whether patterns were similar among different informants, parent's reports were used also. Fourth, the current study is cross-sectional. Longitudinal designs may provide more insight into the causality of relationships. Fifth, most of the relations between temperament and problems found in the current study were similar to those found in other studies. The use of a control group may have provided more detailed information about whether the relationships between temperament and problems differed for children of parents with cancer and those of children in the general population. Finally, the current study did not pay attention to the interaction between children's temperament and other potential predictors, such as parenting, the parentchild relationship and coping. Thomas and Chess introduced the "goodness-of-fit" concept, which means that problems in children arise only when temperament and the expectations of the surroundings are not well adjusted to each other [34].

The fact that temperament of children can have an impact on the prevention of problems by children is important information. Health care providers can use this knowledge to assist parents to take the individual characteristics of the child into account and by means of this to understand their children's behaviour better. Additionally, parents might be supported to improve the 'fit' between the temperament of the child and the consequences of having a parent with cancer.

Acknowledgements The authors would like to acknowledge the financial support received from the Dutch Cancer Society (grant number RUG 2000-2333). We would like to thank Ineke Bakker, who made an important contribution to the collection of data. Finally, we would like to thank the families for participating, as well as the physicians and nurses of the University Medical Centre Groningen for their contribution to patient recruitment.

\section{References}

1. Walker EF, Sabuwalla Z, Huot R (2004) Pubertal neuromaturation, stress sensitivity, and psychopathology. Dev Psychopathol 16:807-824

2. Compas BE, Worsham NL, EppingJordan JE, Grant KE, Mireault G, Howell DC, Malcarne VL (1994) When mom or dad has cancer: markers of psychological distress in cancer patients, spouses, and children. Health Psychol 13:507-515

3. Visser A, Huizinga GA, van der Graaf WTA, Hoekstra HJ, Hoekstra-Weebers JEHM (2004) The impact of parental cancer on children and the family: a review of the literature. Cancer Treat Rev 30:683-694

4. Visser A, Huizinga GA, Hoekstra HJ, van der Graaf WTA, Hoekstra-Weebers JEHM (2006) Parental cancer: characteristics of parents as predictors for child functioning. Cancer 106: 1178-1187
5. Huizinga GA, Visser A, van der Graaf WTA, Hoekstra HJ, Hoekstra-Weebers JEHM (2005) The quality of communication between parents and adolescent children in the case of parental cancer. Ann Oncol 16:1956-1961

6. Watson M, St. James-Roberts I, Ashley S, Tilney C, Brougham B, Edwards L, Baldus C, Romer G (2006) Factors associated with emotional and behavioural problems among school age children of breast cancer patients.

Br J Cancer 94:43-50

7. Compas BE, Connor-Smith JK, Saltzman H, Thomsen AH, Wadsworth ME (2001) Coping with stress during childhood and adolescence: problems, progress, and potential in theory and research. Psychol Bull 127:87-127

8. Bates JEE, Wachs TDE (1994) Temperament: individual differences at the interface of biology and behavior, 13th edn. American Psychological Association, Washington, DC, US

9. Rothbart MK, Bates JE (1998) In: Damon W, Eisenberg W (eds) Temperament. Handbook of child psychology, 5th edn. Wiley, New York, pp 105-176
10. Capaldi DM, Rothbart MK (1992) Development and validation of an early adolescent temperament measure. J Early Adolesc 12:153-173

11. Ellis LK, Rothbart MK (2001) Revision of Early Adolescent Temperament Questionnaire Minneapolis, Minnesota: Biennial Meeting of the Society for Research in Child Development

12. Hartman C (2001) De Nederlandse vertaling van de Early Adolescent Temperament Questionnaire, intern rapport (The Dutch translation of the Early Adolescent Temperament Questionnaire, internal report). Disciplinegroep Psychiatrie, Rijksuniversiteit Groningen

13. Ellis LK (2002) Individual differences and adolescent psychosocial development. Dissertation, University of Oregon

14. Achenbach TM (1991) Manual for the youth self-report and 1991 profiles. University of Vermont Department of Psychiatry, Burlington, VT 
15. Verhulst FC, van der Ende J, Koot HM (1997) Handleiding voor de Youth SelfReport (YSR). (Manual for the YSR) 1st edn. Erasmus University/Department of Child and Adolescent Psychiatry, Sophia Children's Hospital, Rotterdam, The Netherlands

16. Verhulst FC, van der Ende J, Koot HM (1996) Handleiding voor de CBCL/418. Manual for the CBCL/4-18. Sophia kinderziekenhuis/Academisch

Ziekenhuis Rotterdam/Erasmus Universiteit Rotterdam, Rotterdam, The Netherlands

17. Van de Willige G, Schreurs P, Tellegen B, Zwart F (1985) Het Meten Van 'Life-Events': De Vragenlijst Recent Meegemaakte Gebeurtenissen (VRMG) (Assessment of life events: Questionnaire of Recently Experienced Events). Ned Tijdschr Psychol 40:1-19

18. Chatterjee S, Hadi AS, Price B (2000) Regression analysis by example. Wiley, New York

19. Visser A, Huizinga GA, Hoekstra HJ, van der Graaf WTA, Klip EC, Pras E, Hoekstra-Weebers JEHM (2005) Emotional and behavioural functioning of children of a parent diagnosed with cancer: a cross-informant perspective. Psychooncology 14:746-758

20. Kim S, Brody GH, Murry VM (2003) Factor structure of the early adolescent temperament questionnaire and measurement invariance across gender. J Early Adolesc 23:268-294
21. Tuinstra J (1998) Health in adolescence: an empirical study of social inequality in health, health risk behaviour and decision making styles. University of Groningen

22. Eisenberg N, Shepard SA, Fabes RA, Murphy BC, Guthrie IK (1998) Shyness and children's emotionality, regulation, and coping: contemporaneous, longitudinal, and across-context relations. Child Dev 767-790

23. Fox NA, Calkins SD (2003) The development of self-control of emotions: intrinsic and extrinsic influences. Motiv Emot 27:7-26

24. Eisenberg N, Cumberland A, Spinrad TL, Fabes RA, Shepard SA, Reiser M, Murphy BC, Losoya SH, Guthrie IK (2001) The relations of regulation and emotionality to children's externalizing and internalizing problem behavior. Child Dev 1112-1134

25. Rothbart MK, Posner MI, Hershey KL (1995) In: Cicchetti D, Cohen DJ (eds) Temperament, attention, and developmental psychopathology. Developmental psychopathology, vol 1: theory and methods. Wiley series on personality processes. Wiley, Oxford, England, pp 315-340

26. Oldehinkel AJ, Hartman CA, de Winter AF, Veenstra ROJ (2004) Temperament profiles associated with internalizing and externalizing problems in preadolescence. Dev Psychopathol 16:421-440

27. Eisenberg N, Spinrad T, Fabes R, Reiser M, Cumberland A, Shepard S, Valiente C, Losoya S, Guthrie I, Thompson M (2004) The relations of effortful control and impulsivity to children's resiliency and adjustment. Child Dev 75:25-46
28. Merikangas KR, Swendsen JD, Preisig MA, Chazan RZ (1998) Psychopathology and temperament in parents and offspring: results of a family study. J Affect Disord 51:63-74

29. Lengua LJ, Long AC (2002) The role of emotionality and self-regulation in the appraisal-coping process: tests of direct and moderating effects. J Appl Dev Psychol 23:471-493

30. Muris P, Ollendick T (2005) The role of temperament in the etiology of child psychopathology. Clin Child Fam Psychol Rev 8:271-289

31. Birenbaum LK, Yancey DZ, Phillips DS, Chand N, Huster G (1999) Schoolage children's and adolescents' adjustment when a parent has cancer. Oncol Nurs Forum 26:1639-1645

32. Lemery KS, Essex MJ, Smider NA (2002) Revealing the relation between temperament and behavior problem symptoms by eliminating measurement confounding: expert ratings and factor analyses. Child Dev 73:867-882

33. Lengua L, West S, Sandler I (1998) Temperament as predictor of symptomatology in children: addressing contamination of measures. Child Dev 69:164-181

34. Thomas A, Chess S (1977) Temperament and development. Brunner/Mazel, New York 